\title{
Further generalizations of the Banach contraction principle
}

\author{
Mohamed Jleli ${ }^{1}$, Erdal Karapınar ${ }^{2,3}$ and Bessem Samet ${ }^{1 *}$
}

"Correspondence:

bsamet@ksu.edu.sa

${ }^{1}$ Department of Mathematics, King

Saud University, Riyadh, Saudi

Arabia

Full list of author information is

available at the end of the article

\begin{abstract}
We establish a new fixed point theorem in the setting of Branciari metric spaces. The obtained result is an extension of the recent fixed point theorem established in Jleli and Samet (J. Inequal. Appl. 2014:38, 2014).
\end{abstract}

Keywords: fixed point; Branciari metric space; existence; uniqueness

\section{Introduction}

The fixed point theorem, generally known as the Banach contraction principle, appeared in an explicit form in Banach's thesis in 1922 [1], where it was used to establish the existence of a solution to an integral equation. Since then, because of its simplicity and usefulness, it has become a very popular tool in solving existence problems in many branches of mathematical analysis. This principle states that if $(X, d)$ is a complete metric space and $T: X \rightarrow X$ is a contraction map (i.e., $d(T x, T y) \leq \lambda d(x, y)$ for all $x, y \in X$, where $\lambda \in(0,1)$ is a constant), then $T$ has a unique fixed point.

The Banach contraction principle has been generalized in many ways over the years. In some generalizations, the contractive nature of the map is weakened; see [2-9] and others. In other generalizations, the topology is weakened; see [10-23] and others. In [24], Nadler extended the Banach fixed point theorem from single-valued maps to set-valued contractive maps. Other fixed point results for set-valued maps can be found in [25-30] and the references therein.

In 2000, Branciari [11] introduced the concept of generalized metric spaces, where the triangle inequality is replaced by the inequality $d(x, y) \leq d(x, u)+d(u, v)+d(v, y)$ for all pairwise distinct points $x, y, u, v \in X$. Various fixed point results were established on such spaces; see $[10,13,17-20,22,31-33]$ and the references therein.

We recall the following definitions introduced in [11].

Definition 1.1 Let $X$ be a non-empty set and $d: X \times X \rightarrow[0, \infty)$ be a mapping such that for all $x, y \in X$ and for all distinct points $u, v \in X$, each of them different from $x$ and $y$, one has

(i) $d(x, y)=0 \Longleftrightarrow x=y$;

(ii) $d(x, y)=d(y, x)$;

(iii) $d(x, y) \leq d(x, u)+d(u, v)+d(v, y)$.

Then $(X, d)$ is called a generalized metric space (or for short g.m.s). 
Definition 1.2 Let $(X, d)$ be a g.m.s, $\left\{x_{n}\right\}$ be a sequence in $X$ and $x \in X$. We say that $\left\{x_{n}\right\}$ is convergent to $x$ if and only if $d\left(x_{n}, x\right) \rightarrow 0$ as $n \rightarrow \infty$. We denote this by $x_{n} \rightarrow x$.

Definition 1.3 Let $(X, d)$ be a g.m.s and $\left\{x_{n}\right\}$ be a sequence in $X$. We say that $\left\{x_{n}\right\}$ is Cauchy if and only if $d\left(x_{n}, x_{m}\right) \rightarrow 0$ as $n, m \rightarrow \infty$.

Definition 1.4 Let $(X, d)$ be a g.m.s. We say that $(X, d)$ is complete if and only if every Cauchy sequence in $X$ converges to some element in $X$.

The following result was established in [17] (see also [34]).

Lemma 1.1 Let $(X, d)$ be a g.m.s and $\left\{x_{n}\right\}$ be a Cauchy sequence in $(X, d)$ such that $d\left(x_{n}, x\right) \rightarrow 0$ as $n \rightarrow \infty$ for some $x \in X$. Then $d\left(x_{n}, y\right) \rightarrow d(x, y)$ as $n \rightarrow \infty$ for all $y \in X$. In particular, $\left\{x_{n}\right\}$ does not converge to $y$ if $y \neq x$.

We denote by $\Theta$ the set of functions $\theta:(0, \infty) \rightarrow(1, \infty)$ satisfying the following conditions:

$\left(\Theta_{1}\right) \theta$ is non-decreasing;

$\left(\Theta_{2}\right)$ for each sequence $\left\{t_{n}\right\} \subset(0, \infty), \lim _{n \rightarrow \infty} \theta\left(t_{n}\right)=1$ if and only if $\lim _{n \rightarrow \infty} t_{n}=0^{+}$;

$\left(\Theta_{3}\right)$ there exist $r \in(0,1)$ and $\ell \in(0, \infty]$ such that $\lim _{t \rightarrow 0^{+}} \frac{\theta(t)-1}{t^{r}}=\ell$;

$\left(\Theta_{4}\right) \theta$ is continuous.

Recently, Jleli and Samet [35] established the following generalization of the Banach fixed point theorem in the setting of Branciari metric spaces.

Theorem 1.1 (Jleli and Samet [35]) Let $(X, d)$ be a complete g.m.s and $T: X \rightarrow X$ be a given map. Suppose that there exist $\theta \in \Theta$ and $k \in(0,1)$ such that

$$
x, y \in X, \quad d(T x, T y) \neq 0 \quad \Longrightarrow \quad \theta(d(T x, T y)) \leq[\theta(d(x, y))]^{k} .
$$

Then $T$ has a unique fixed point.

Note that the condition $\left(\Theta_{4}\right)$ is not supposed in Theorem 1.1.

The aim of this paper is to extend the result given by Theorem 1.1.

\section{Result and proof}

Now, we are ready to state and prove our main result.

Theorem 2.1 Let $(X, d)$ be a complete g.m.s and $T: X \rightarrow X$ be a given map. Suppose that there exist $\theta \in \Theta$ and $k \in(0,1)$ such that

$$
x, y \in X, \quad d(T x, T y) \neq 0 \quad \Longrightarrow \quad \theta(d(T x, T y)) \leq[\theta(M(x, y))]^{k},
$$

where

$$
M(x, y)=\max \{d(x, y), d(x, T x), d(y, T y)\} .
$$

Then $T$ has a unique fixed point. 
Proof Let $x \in X$ be an arbitrary point in $X$. If for some $p \in \mathbb{N}$ we have $T^{p} x=T^{p+1} x$, then $T^{p} x$ will be a fixed point of $T$. So, without restriction of the generality, we can suppose that $d\left(T^{n} x, T^{n+1} x\right)>0$ for all $n \in \mathbb{N}$. Now, from (1), for all $n \in \mathbb{N}$, we have

$$
\theta\left(d\left(T^{n} x, T^{n+1} x\right)\right) \leq\left[\theta\left(M\left(T^{n-1} x, T^{n} x\right)\right)\right]^{k},
$$

where from (2)

$$
\begin{aligned}
M\left(T^{n-1} x, T^{n} x\right) & =\max \left\{d\left(T^{n-1} x, T^{n} x\right), d\left(T^{n-1} x, T T^{n-1} x\right), d\left(T^{n} x, T T^{n} x\right)\right\} \\
& =\max \left\{d\left(T^{n-1} x, T^{n} x\right), d\left(T^{n-1} x, T^{n} x\right), d\left(T^{n} x, T^{n+1} x\right)\right\} \\
& =\max \left\{d\left(T^{n-1} x, T^{n} x\right), d\left(T^{n} x, T^{n+1} x\right)\right\} .
\end{aligned}
$$

If $M\left(T^{n-1} x, T^{n} x\right)=d\left(T^{n} x, T^{n+1} x\right)$, then inequality (3) turns into

$$
\theta\left(d\left(T^{n} x, T^{n+1} x\right)\right) \leq\left[\theta\left(d\left(T^{n} x, T^{n+1} x\right)\right)\right]^{k},
$$

which implies that

$$
\ln \left[\theta\left(d\left(T^{n} x, T^{n+1} x\right)\right)\right] \leq k \ln \left[\theta\left(d\left(T^{n} x, T^{n+1} x\right)\right)\right]
$$

that is a contradiction with $k \in(0,1)$. Hence, from (4) we have $M\left(T^{n-1} x, T^{n} x\right)=d\left(T^{n-1} x\right.$, $T^{n} x$ ), and inequality (3) yields

$$
\begin{aligned}
\theta\left(d\left(T^{n} x, T^{n+1} x\right)\right) & \leq\left[\theta\left(d\left(T^{n-1} x, T^{n} x\right)\right)\right]^{k} \\
& \leq\left[\theta\left(d\left(T^{n-2} x, T^{n-1} x\right)\right)\right]^{k^{2}} \leq \cdots \leq[\theta(d(x, T x))]^{k^{n}} .
\end{aligned}
$$

Thus we have

$$
1 \leq \theta\left(d\left(T^{n} x, T^{n+1} x\right)\right) \leq[\theta(d(x, T x))]^{k^{n}} \quad \text { for all } n \in \mathbb{N} .
$$

Letting $n \rightarrow \infty$ in (5), we obtain

$$
\theta\left(d\left(T^{n} x, T^{n+1} x\right)\right) \rightarrow 1 \quad \text { as } n \rightarrow \infty,
$$

which implies from $\left(\Theta_{2}\right)$ that

$$
\lim _{n \rightarrow \infty} d\left(T^{n} x, T^{n+1} x\right)=0 .
$$

From condition $\left(\Theta_{3}\right)$, there exist $r \in(0,1)$ and $\ell \in(0, \infty]$ such that

$$
\lim _{n \rightarrow \infty} \frac{\theta\left(d\left(T^{n} x, T^{n+1} x\right)\right)-1}{\left[d\left(T^{n} x, T^{n+1} x\right)\right]^{r}}=\ell .
$$

Suppose that $\ell<\infty$. In this case, let $B=\ell / 2>0$. From the definition of the limit, there exists $n_{0} \in \mathbb{N}$ such that

$$
\left|\frac{\theta\left(d\left(T^{n} x, T^{n+1} x\right)\right)-1}{\left[d\left(T^{n} x, T^{n+1} x\right)\right]^{r}}-\ell\right| \leq B \quad \text { for all } n \geq n_{0} .
$$


This implies that

$$
\frac{\theta\left(d\left(T^{n} x, T^{n+1} x\right)\right)-1}{\left[d\left(T^{n} x, T^{n+1} x\right)\right]^{r}} \geq \ell-B=B \quad \text { for all } n \geq n_{0} .
$$

Then

$$
n\left[d\left(T^{n} x, T^{n+1} x\right)\right]^{r} \leq A n\left[\theta\left(d\left(T^{n} x, T^{n+1} x\right)\right)-1\right] \text { for all } n \geq n_{0}
$$

where $A=1 / B$.

Suppose now that $\ell=\infty$. Let $B>0$ be an arbitrary positive number. From the definition of the limit, there exists $n_{0} \in \mathbb{N}$ such that

$$
\frac{\theta\left(d\left(T^{n} x, T^{n+1} x\right)\right)-1}{\left[d\left(T^{n} x, T^{n+1} x\right)\right]^{r}} \geq B \quad \text { for all } n \geq n_{0} .
$$

This implies that

$$
n\left[d\left(T^{n} x, T^{n+1} x\right)\right]^{r} \leq A n\left[\theta\left(d\left(T^{n} x, T^{n+1} x\right)\right)-1\right] \text { for all } n \geq n_{0},
$$

where $A=1 / B$.

Thus, in all cases, there exist $A>0$ and $n_{0} \in \mathbb{N}$ such that

$$
n\left[d\left(T^{n} x, T^{n+1} x\right)\right]^{r} \leq A n\left[\theta\left(d\left(T^{n} x, T^{n+1} x\right)\right)-1\right] \text { for all } n \geq n_{0} .
$$

Using (5), we obtain

$$
n\left[d\left(T^{n} x, T^{n+1} x\right)\right]^{r} \leq A n\left([\theta(d(x, T x))]^{k^{n}}-1\right) \quad \text { for all } n \geq n_{0} .
$$

Letting $n \rightarrow \infty$ in the above inequality, we obtain

$$
\lim _{n \rightarrow \infty} n\left[d\left(T^{n} x, T^{n+1} x\right)\right]^{r}=0 .
$$

Thus, there exists $n_{1} \in \mathbb{N}$ such that

$$
d\left(T^{n} x, T^{n+1} x\right) \leq \frac{1}{n^{1 / r}} \quad \text { for all } n \geq n_{1} .
$$

Now, we shall prove that $T$ has a periodic point. Suppose that it is not the case, then $T^{n} x \neq T^{m} x$ for every $n, m \in \mathbb{N}$ such that $n \neq m$. Using (1), we obtain

$$
\theta\left(d\left(T^{n} x, T^{n+2} x\right)\right) \leq\left[\theta\left(M\left(T^{n-1} x, T^{n+1} x\right)\right)\right]^{k}
$$

where from (2)

$$
M\left(T^{n-1} x, T^{n+1} x\right)=\max \left\{d\left(T^{n-1} x, T^{n+1} x\right), d\left(T^{n-1} x, T^{n} x\right), d\left(T^{n+1} x, T^{n+2} x\right)\right\} .
$$


Since $\theta$ is non-decreasing, we obtain from (8) and (9)

$$
\begin{aligned}
\theta\left(d\left(T^{n} x, T^{n+2} x\right)\right) \leq & {\left[\operatorname { m a x } \left\{\theta\left(d\left(T^{n-1} x, T^{n+1} x\right)\right), \theta\left(d\left(T^{n-1} x, T^{n} x\right)\right),\right.\right.} \\
& \left.\left.\theta\left(d\left(T^{n+1} x, T^{n+2} x\right)\right)\right\}\right]^{k} .
\end{aligned}
$$

Let $I$ be the set of $n \in \mathbb{N}$ such that

$$
\begin{aligned}
u_{n} & :=\max \left\{\theta\left(d\left(T^{n-1} x, T^{n+1} x\right)\right), \theta\left(d\left(T^{n-1} x, T^{n} x\right)\right), \theta\left(d\left(T^{n+1} x, T^{n+2} x\right)\right)\right\} \\
& =\theta\left(d\left(T^{n-1} x, T^{n+1} x\right)\right) .
\end{aligned}
$$

If $|I|<\infty$, then there exists $N \in \mathbb{N}$ such that for every $n \geq N$,

$$
\begin{aligned}
& \max \left\{\theta\left(d\left(T^{n-1} x, T^{n+1} x\right)\right), \theta\left(d\left(T^{n-1} x, T^{n} x\right)\right), \theta\left(d\left(T^{n+1} x, T^{n+2} x\right)\right)\right\} \\
& \quad=\max \left\{\theta\left(d\left(T^{n-1} x, T^{n} x\right)\right), \theta\left(d\left(T^{n+1} x, T^{n+2} x\right)\right)\right\} .
\end{aligned}
$$

In this case, we obtain from (10)

$$
1 \leq \theta\left(d\left(T^{n} x, T^{n+2} x\right)\right) \leq\left[\max \left\{\theta\left(d\left(T^{n-1} x, T^{n} x\right)\right), \theta\left(d\left(T^{n+1} x, T^{n+2} x\right)\right)\right\}\right]^{k}
$$

for all $n \geq N$. Letting $n \rightarrow \infty$ in the above inequality and using (6), we get

$$
\theta\left(d\left(T^{n} x, T^{n+2} x\right)\right) \rightarrow 1 \quad \text { as } n \rightarrow \infty .
$$

If $|I|=\infty$, we can find a subsequence of $\left\{u_{n}\right\}$, that we denote also by $\left\{u_{n}\right\}$, such that

$$
u_{n}=\theta\left(d\left(T^{n-1} x, T^{n+1} x\right)\right) \quad \text { for } n \text { large enough. }
$$

In this case, we obtain from (10)

$$
\begin{aligned}
1 & \leq \theta\left(d\left(T^{n} x, T^{n+2} x\right)\right) \leq\left[\theta\left(d\left(T^{n-1} x, T^{n+1} x\right)\right)\right]^{k} \\
& \leq\left[\theta\left(d\left(T^{n-2} x, T^{n} x\right)\right)\right]^{k^{2}} \leq \cdots \leq\left[\theta\left(d\left(x, T^{2} x\right)\right)\right]^{k^{n}}
\end{aligned}
$$

for $n$ large enough. Letting $n \rightarrow \infty$ in the above inequality, we obtain

$$
\theta\left(d\left(T^{n} x, T^{n+2} x\right)\right) \rightarrow 1 \quad \text { as } n \rightarrow \infty .
$$

Then in all cases, (11) holds. Using (11) and the property $\left(\Theta_{2}\right)$, we obtain

$$
\lim _{n \rightarrow \infty} d\left(T^{n} x, T^{n+2} x\right)=0
$$

Similarly, from condition $\left(\Theta_{3}\right)$, there exists $n_{2} \in \mathbb{N}$ such that

$$
d\left(T^{n} x, T^{n+2} x\right) \leq \frac{1}{n^{1 / r}} \quad \text { for all } n \geq n_{2} .
$$

Let $\mathcal{N}=\max \left\{n_{0}, n_{1}\right\}$. We consider two cases. 
Case 1. If $m>2$ is odd, then writing $m=2 L+1, L \geq 1$, using (7), for all $n \geq \mathcal{N}$, we obtain

$$
\begin{aligned}
d\left(T^{n} x, T^{n+m} x\right) & \leq d\left(T^{n} x, T^{n+1} x\right)+d\left(T^{n+1} x, T^{n+2} x\right)+\cdots+d\left(T^{n+2 L} x, T^{n+2 L+1} x\right) \\
& \leq \frac{1}{n^{1 / r}}+\frac{1}{(n+1)^{1 / r}}+\cdots+\frac{1}{(n+2 L)^{1 / r}} \\
& \leq \sum_{i=n}^{\infty} \frac{1}{i^{1 / r}} .
\end{aligned}
$$

Case 2. If $m>2$ is even, then writing $m=2 L, L \geq 2$, using (7) and (12), for all $n \geq \mathcal{N}$, we obtain

$$
\begin{aligned}
d\left(T^{n} x, T^{n+m} x\right) & \leq d\left(T^{n} x, T^{n+2} x\right)+d\left(T^{n+2} x, T^{n+3} x\right)+\cdots+d\left(T^{n+2 L-1} x, T^{n+2 L} x\right) \\
& \leq \frac{1}{n^{1 / r}}+\frac{1}{(n+2)^{1 / r}}+\cdots+\frac{1}{(n+2 L-1)^{1 / r}} \\
& \leq \sum_{i=n}^{\infty} \frac{1}{i^{1 / r}} .
\end{aligned}
$$

Thus, combining all the cases, we have

$$
d\left(T^{n} x, T^{n+m} x\right) \leq \sum_{i=n}^{\infty} \frac{1}{i^{1 / r}} \quad \text { for all } n \geq \mathcal{N}, m \in \mathbb{N}
$$

From the convergence of the series $\sum_{i} \frac{1}{i^{1 / r}}$ (since $1 / r>1$ ), we deduce that $\left\{T^{n} x\right\}$ is a Cauchy sequence. Since $(X, d)$ is complete, there is $z \in X$ such that $T^{n} x \rightarrow z$ as $n \rightarrow \infty$. Without restriction of the generality, we can suppose that $T^{n} x \neq z$ for all $n$ (or for $n$ large enough). Suppose that $d(z, T z)>0$, using (1), we get

$$
\theta\left(d\left(T^{n+1} x, T z\right)\right) \leq\left[\theta\left(M\left(T^{n} x, z\right)\right)\right]^{k} \quad \text { for all } n \in \mathbb{N}
$$

where

$$
M\left(T^{n} x, z\right)=\max \left\{d\left(T^{n} x, z\right), d\left(T^{n} x, T^{n+1} x\right), d(z, T z)\right\} .
$$

Letting $n \rightarrow \infty$ in the above inequality, using $\left(\Theta_{4}\right)$ and Lemma 1.1, we obtain

$$
\theta(d(z, T z)) \leq[\theta(d(z, T z))]^{k}<\theta(d(z, T z))
$$

which is a contradiction. Thus we have $z=T z$, which is also a contradiction with the assumption: $T$ does not have a periodic point. Thus $T$ has a periodic point, $\operatorname{say} z$, of period $q$. Suppose that the set of fixed points of $T$ is empty. Then we have

$$
q>1 \text { and } d(z, T z)>0 .
$$

Using (1), we obtain

$$
\theta(d(z, T z))=\theta\left(d\left(T^{q} z, T^{q+1} z\right)\right) \leq[\theta(z, T z)]^{k^{q}}<\theta(d(z, T z))
$$


which is a contradiction. Thus, the set of fixed points of $T$ is non-empty, that is, $T$ has at least one fixed point. Now, suppose that $z, u \in X$ are two fixed points of $T$ such that $d(z, u)=d(T z, T u)>0$. Using $(1)$, we obtain

$$
\theta(d(z, u))=\theta(d(T z, T u)) \leq[\theta(d(z, u))]^{k}<\theta(d(z, u))
$$

which is a contradiction. Then we have one and only one fixed point.

\section{Some consequences}

We start by deducing the following fixed point result.

Corollary 3.1 Let $(X, d)$ be a complete g.m.s and $T: X \rightarrow X$ be a given map. Suppose that there exists $\lambda \in(0,1)$ such that

$$
d(T x, T y) \leq \lambda \max \{d(x, y), d(x, T x), d(y, T y)\} \quad \text { for all } x, y \in X
$$

Then T has a unique fixed point.

Proof From (13), we have

$$
e^{\sqrt{d(T x, T y)}} \leq\left[e^{\sqrt{\max \{d(x, y), d(x, T x), d(y, T y)\}}}\right]^{\sqrt{\lambda}} \text { for all } x, y \in X
$$

Clearly the function $\theta:(0, \infty) \rightarrow(1, \infty)$ defined by $\theta(t):=e^{\sqrt{t}}$ belongs to $\Theta$. So, the existence and uniqueness of the fixed point follows from Theorem 2.1.

The following fixed point result established in [11] is an immediate consequence of Corollary 3.1 .

Corollary 3.2 Let $(X, d)$ be a complete g.m.s and $T: X \rightarrow X$ be a given map. Suppose that there exists $\lambda \in(0,1)$ such that

$$
d(T x, T y) \leq \lambda d(x, y) \quad \text { for all } x, y \in X
$$

Then T has a unique fixed point.

The following fixed point result established in [34] is an immediate consequence of Corollary 3.1.

Corollary 3.3 Let $(X, d)$ be a complete g.m.s and $T: X \rightarrow X$ be a given map. Suppose that there exist $\lambda, \mu \geq 0$ with $\lambda+\mu<1$ such that

$$
d(T x, T y) \leq \lambda d(x, T x)+\mu d(y, T y) \quad \text { for all } x, y \in X
$$

Then T has a unique fixed point.

The following fixed point result is also an immediate consequence of Corollary 3.1. 
Corollary 3.4 Let $(X, d)$ be a complete g.m.s and $T: X \rightarrow X$ be a given map. Suppose that there exist $\lambda, \mu, v \geq 0$ with $\lambda+\mu+v<1$ such that

$$
d(T x, T y) \leq \lambda d(x, y)+\mu d(x, T x)+v d(y, T y) \quad \text { for all } x, y \in X .
$$

Then $T$ has a unique fixed point.

We note that $\Theta$ contains a large class of functions. For example, for

$$
\theta(t):=2-\frac{2}{\pi} \arctan \left(\frac{1}{t^{\alpha}}\right), \quad 0<\alpha<1, t>0
$$

we obtain from Theorem 2.1 the following result.

Corollary 3.5 Let $(X, d)$ be a complete g.m.s and $T: X \rightarrow X$ be a given map. Suppose that there exist $\alpha, k \in(0,1)$ such that

$$
2-\frac{2}{\pi} \arctan \left(\frac{1}{[d(T x, T y)]^{\alpha}}\right) \leq\left[2-\frac{2}{\pi} \arctan \left(\frac{1}{[M(x, y)]^{\alpha}}\right)\right]^{k} \text { for all } x, y \in X, T x \neq T y \text {, }
$$

where $M(x, y)$ is given by (2). Then T has a unique fixed point.

Finally, since a metric space is a g.m.s, from Theorem 2.1 we deduce immediately the following result.

Corollary 3.6 Let $(X, d)$ be a complete metric space and $T: X \rightarrow X$ be a given map. Suppose that there exist $\theta \in \Theta$ and $k \in(0,1)$ such that

$$
x, y \in X, \quad d(T x, T y) \neq 0 \quad \Longrightarrow \quad \theta(d(T x, T y)) \leq[\theta(M(x, y))]^{k},
$$

where $M(x, y)$ is given by (2). Then T has a unique fixed point.

Competing interests

The authors declare that they have no competing interests.

\section{Authors' contributions}

All authors contributed equally and significantly in writing this article. All authors read and approved the final manuscript.

\section{Author details}

${ }^{1}$ Department of Mathematics, King Saud University, Riyadh, Saudi Arabia. ${ }^{2}$ Department of Mathematics, Atilim University, Incek, Ankara, 06836, Turkey. ${ }^{3}$ Nonlinear Analysis and Applied Mathematics Research Group (NAAM), King Abdulaziz University, Jeddah, Saudi Arabia.

\section{Acknowledgements}

The first and third authors would like to extend their sincere appreciation to the Deanship of Scientific Research at King Saud University for its funding of this research through the Research Group Project No: RG-1435-034.

Received: 30 July 2014 Accepted: 10 October 2014 Published: 2 November 2014

\section{References}

1. Banach, S: Sur les opérations dans les ensembles abstraits et leur applications aux équations intégrales. Fundam. Math. 3, 133-181 (1922)

2. Boyd, DW, Wong, JSW: On nonlinear contractions. Proc. Am. Math. Soc. 20, 458-464 (1969)

3. Ćirić, L: A generalization of Banach's contraction principle. Proc. Am. Math. Soc. 45(2), 267-273 (1974)

4. Kirk, WA: Fixed points of asymptotic contractions. J. Math. Anal. Appl. 277, 645-650 (2003) 
5. Meir, A, Keeler, E: A theorem on contraction mappings. J. Math. Anal. Appl. 28, 326-329 (1969)

6. Rakotch, E: A note on contractive mappings. Proc. Am. Math. Soc. 13, 459-465 (1962)

7. Reich, S: Fixed points of contractive functions. Boll. Unione Mat. Ital. 5, 26-42 (1972)

8. Suzuki, T: Fixed point theorem for asymptotic contractions of Meir-Keeler type in complete metric spaces. Nonlinear Anal. 64, 971-978 (2006)

9. Wardowski, D: Fixed points of a new type of contractive mappings in complete metric spaces. Fixed Point Theory Appl. 2012, Article ID 94 (2012)

10. Di Bari, C, Vetro, P: Common fixed points in generalized metric spaces. Appl. Math. Comput. 218(13), 7322-7325 (2012)

11. Branciari, A: A fixed point theorem of Banach-Caccioppoli type on a class of generalized metric spaces. Publ. Math. (Debr.) 57, 31-37 (2000)

12. Cherichi, M, Samet, B: Fixed point theorems on ordered gauge spaces with applications to nonlinear integral equations. Fixed Point Theory Appl. 2012, Article ID 13 (2012)

13. Das, P: A fixed point theorem on a class of generalized metric spaces. Korean J. Math. Sci. 9, 29-33 (2002)

14. Frigon, M: Fixed point results for generalized contractions in gauge spaces and applications. Proc. Am. Math. Soc. $128,2957-2965$ (2000)

15. Janković, S, Kadelburg, Z, Radenović, S: On cone metric spaces: a survey. Nonlinear Anal. 74, $2591-2601$ (2011)

16. Khamsi, MA, Kozlowski, WM, Reich, S: Fixed point theory in modular function spaces. Nonlinear Anal. 14(11), 935-953 (1990)

17. Kirk, WA, Shahzad, N: Generalized metrics and Caristi's theorem. Fixed Point Theory Appl. 2013, Article ID 129 (2013)

18. Lakzian, H, Samet, B: Fixed points for $(\psi, \varphi)$-weakly contractive mappings in generalized metric spaces. Appl. Math. Lett. 25(5), 902-906 (2012)

19. Samet, B: Discussion on: A fixed point theorem of Banach-Caccioppoli type on a class of generalized metric spaces, by A. Branciari. Publ. Math. (Debr.) 76(4), 493-494 (2010)

20. Sarama, IR, Rao, JM, Rao, SS: Contractions over generalized metric spaces. J. Nonlinear Sci. Appl. 2(3), 180-182 (2009)

21. Tarafdar, E: An approach to fixed point theorems on uniform spaces. Trans. Am. Math. Soc. 191, $209-225$ (1974)

22. Turinici, M: Functional contractions in local Branciari metric spaces (2012). arXiv:1208.4610v1 [math.GN]

23. Vetro, C: On Branciari's theorem for weakly compatible mappings. Appl. Math. Lett. 23(6), 700-705 (2010)

24. Nadler, SB Jr.: Multi-valued contraction mappings. Pac. J. Math. 30, 475-488 (1969)

25. Berinde, M, Berinde, V: On a general class of multi-valued weakly Picard mappings. J. Math. Anal. Appl. 326, 772-782 (2007)

26. Ćirić, L: Multi-valued nonlinear contraction mappings. Nonlinear Anal. 71, 2716-2723 (2009)

27. Markin, JT: A fixed point theorem for set-valued mappings. Bull. Am. Math. Soc. 74, 639-640 (1968)

28. Mizoguchi, N, Takahashi, W: Fixed point theorems for multivalued mappings on complete metric spaces. J. Math. Anal. Appl. 141, 177-188 (1989)

29. Naidu, SVR: Fixed point theorems for a broad class of multimaps. Nonlinear Anal. 52, 961-969 (2003)

30. Zhang, CK, Zhu, J, Zhao, PH: An extension of multi-valued contraction mappings and fixed points. Proc. Am. Math. Soc. 128, 2439-2444 (2000)

31. Karapınar, E: Fixed points results for alpha-admissible mapping of integral type on generalized metric spaces. Abstr. Appl. Anal. 2014, Article ID 141409 (2014)

32. Karapınar, E: Discussion on contractions on generalized metric spaces. Abstr. Appl. Anal. 2014, Article ID 962784 (2014)

33. La Rosa, V, Vetro, P: Common fixed points for $\alpha-\psi-\varphi$-contractions in generalized metric spaces. Nonlinear Anal., Model. Control 19(1), 43-54 (2014)

34. Jleli, M, Samet, B: The Kannan's fixed point theorem in a cone rectangular metric space. J. Nonlinear Sci. Appl. 2(3), 161-167 (2009)

35. Jleli, M, Samet, B: A new generalization of the Banach contraction principle. J. Inequal. Appl. 2014, Article ID 38 (2014)

doi:10.1186/1029-242X-2014-439

Cite this article as: Jleli et al.: Further generalizations of the Banach contraction principle. Journal of Inequalities and Applications 2014 2014:439.

\section{Submit your manuscript to a SpringerOpen ${ }^{\circ}$ journal and benefit from:}

- Convenient online submission

- Rigorous peer review

- Immediate publication on acceptance

- Open access: articles freely available online

- High visibility within the field

- Retaining the copyright to your article

Submit your next manuscript at $>$ springeropen.com 